\title{
Article \\ Reduced Graphene Oxide Aerogels with \\ Functionalization-Mediated Disordered Stacking for Sodium-Ion Batteries
}

\author{
Jaehyeung Park ${ }^{1,2} \mathbb{D}^{-}$, Jaswinder Sharma ${ }^{1}$, Charl J. Jafta ${ }^{1}{ }^{1}$, Lilin $\mathrm{He}^{3}$, Harry M. Meyer III ${ }^{4}$, Jianlin Li ${ }^{1}$,

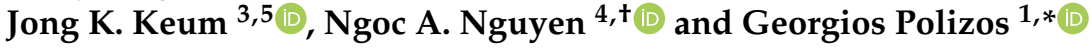

1 Electrification and Energy Infrastructures Division, Oak Ridge National Laboratory, Oak Ridge, TN 37831, USA; parkj@knu.ac.kr (J.P.); sharmajk@ornl.gov (J.S.); jaftacj@ornl.gov (C.J.J.); lij4@ornl.gov (J.L.)

2 Department of Bio-Fibers and Materials Science, Kyungpook National University, Daegu 41566, Korea

3 Neutron Scattering Division, Oak Ridge National Laboratory, Oak Ridge, TN 37831, USA; hel3@ornl.gov (L.H.); keumjk@ornl.gov (J.K.K.)

4 Chemical Sciences Division, Oak Ridge National Laboratory, Oak Ridge, TN 37831, USA; meyerhmiii@ornl.gov (H.M.M.III); nanguyen@illinois.edu (N.A.N.)

5 Center for Nanophase Materials Sciences, Oak Ridge National Laboratory, Oak Ridge, TN 37831, USA

* Correspondence: polyzosg@ornl.gov

+ Current address: Applied Research Institute, University of Illinois at Urbana-Champaign, 2100 S Oak St., Champaign, IL 61820, USA.

\section{check for}

updates

Citation: Park, J.; Sharma, J.; Jafta,

C.J.; He, L.; Meyer, H.M., III; Li, J.;

Keum, J.K.; Nguyen, N.A.; Polizos, G. Reduced Graphene Oxide Aerogels with Functionalization-Mediated Disordered Stacking for Sodium-Ion Batteries. Batteries 2022, 8, 12 https://doi.org/10.3390/ batteries 8020012

Academic Editors: Emma Kendrick Lin Chen and Brij Kishore

Received: 24 November 2021

Accepted: 30 January 2022

Published: 1 February 2022

Publisher's Note: MDPI stays neutral with regard to jurisdictional claims in published maps and institutional affiliations.

Copyright: (C) 2022 by the authors. Licensee MDPI, Basel, Switzerland. This article is an open access article distributed under the terms and conditions of the Creative Commons Attribution (CC BY) license (https:// creativecommons.org/licenses/by/ $4.0 /)$.
Abstract: Surface modified reduced graphene oxide ( $\mathrm{rGO}$ ) aerogels were synthesized using the hydrothermal method. Ethylene diamine (EDA) and $\alpha$-cyclodextrin (CD) were used to functionalize the surface of the graphene oxide layers. The oxygen reduction and surface modification occurred in-situ during the hydrothermal self-assembly process. The chemical functionality and structure of the resulting ethylene diamine modified (rGO-EDA) and cyclodextrin modified (rGO-CD) aerogels as well as of the pristine unmodified rGO aerogel were studied using XPS, SEM, XRD, and SANS techniques. The overall surface composition showed a significant decrease in the oxygen content for all synthesized aerogels. The surface modified aerogels were characterized by a disordered stacking of the assembled rGO layers. The surface functionalities resulted in a broad distribution of the interlayer spacing and introduced structural heterogeneities. Such disordered structures can enable a better adsorption mechanism of the sodium ions. Coin cells based on the synthesized aerogels and sodium metal were assembled and tested at several charge and discharge rates. The correlation between the surface functionality of the rGO, the induced structural heterogeneities due to the disordered stacking, and the electrochemical performance of sodium-ion batteries were investigated. Operando XRD measurements were carried out during the battery cycling to investigate the adsorption or intercalation nature of the sodiation mechanism.

Keywords: reduced graphene oxide; aerogel; hydrothermal; sodium-ion batteries

\section{Introduction}

High performance electrochemical energy storage devices are in high demand due to the recent technological advances in the transportation and consumer electrics sectors [1-5]. Among various technologies, lithium-ion rechargeable batteries have been established as the most widespread type of batteries for energy storage devices. The increasing demand for low-cost commercial energy storage devices has driven significant research studies to identify new materials that can potentially reduce the cost and improve the electrochemical properties of current lithium-ion technologies [6-9]. Among them, sodium-ion batteries have recently attracted the scientific attention due to the natural abundance and low cost of sodium and the similar electrochemical mechanism with the lithium-ion batteries [10-18]. 
Additional advantages for the development of the sodium-ion batteries are associated with the utilization of the infrastructure and technologies that were established for the commercialization of the lithium-ion batteries [19-22].

The main challenges of the sodium-ion batteries are related to the limitations in the $\mathrm{Na}^{+}$diffusion due to the larger atomic size of the $\mathrm{Na}^{+}$compared to the $\mathrm{Li}^{+}$ions and the unstable intercalation of the $\mathrm{Na}^{+}$in graphite structures [23,24]. To overcome these performance barriers and implement sodium-ion batteries with high-capacity and good cycling stability [25-30] it is imperative to design advanced electrode structures with excellent electrochemical properties, high structural stability, and high electrical conductivity. Threedimensional (3D) carbon structures such as graphene or reduced graphene oxide (rGO) aerogels are strong candidate materials for electrodes due to their superior electrochemical and mechanical properties as well as due to their high specific surface area [31-34]. Such 3D structures can be prepared by hydrothermally assisted self-assembly [35], templating [36], or chemical vapor deposition (CVD) [37]. The interconnected carbon platelet network can provide open channels for the easy access of the electrolyte and multiple channels for fast electron transport [35-39]. For sodium-ion batteries, the rGO assembly configuration can facilitate the sodiation and desodiation mechanism during the electrochemical cycling. Unlike non-graphitizable carbons (or hard carbons), the disordered stacking of the assembled rGO platelets and the formation of long-range defects can be tailored through the surface functionalization of the rGO. The micro-pore structure of the assembled graphene layers plays an important role in the electrochemical performance of the electrode by controlling the $\mathrm{Na}^{+}$transport mechanism [31-33]. The $\mathrm{Na}^{+}$ions can be adsorbed on the surface of the assembled porous graphene layers that can easily be accessible by the electrolyte. Doping the graphene aerogels with electronegative atoms like nitrogen or encapsulating nanoparticles between the graphene layers has shown to enhance the electrochemical performance of the sodium-ion battery [40-43]. Defects on the graphene surface that were created during the doping process have shown to assist the transport properties of the $\mathrm{Na}^{+}$ions [43]. Electrode structures based on $\mathrm{rGO}, \mathrm{TiO}_{2}$, and nitrogen doped carbon foams (the latter can be derived from the pyrolysis of melamine foam) have also been studied $[44,45]$.

A significant drawback in the design of graphite electrodes for $\mathrm{Na}^{+}$ion batteries is the energetically unfavorable formation of sodium-graphite intercalation compounds according to first-principles calculations $[23,24]$. In absence of $\mathrm{Na}^{+}$intercalation, a disordered assembly of the rGO layers may increase the rGO surface area that is accessible by the $\mathrm{Na}^{+}$ions. This configuration is expected to enhance the $\mathrm{Na}^{+}$ion adsorption on the interconnected rGO channels and improve the electrochemical performance of the sodium-ion battery. To validate this supposition, short polymer groups were covalently bonded on the rGO surface. Self-assembled rGO aerogels with functionalization-driven disordered stacking were synthesized. The surface functionalities were introduced to covalently interconnect the rGO layers, hinder their ordered assembly and create defects during the hydrothermal reaction. The covalently bonding and reduction of the GO were implemented in-situ during the one-step hydrothermal reaction. Ethylenediamine (EDA) and $\alpha$-cyclodextrin (CD) were used for the surface modification of the rGO. In addition to the heterogeneous assembly due to steric constraints, the surface functionalities introduced nitrogen (EDA functionality) and additional oxygen (CD functionality) atoms in the interlayer space of the rGO assemblies. The EDA functionality was used as a facile alternative to the N-doped carbon structures. The $\alpha$-cyclodextrin is the smallest cyclic oligomer compared to the $\beta$ and $\gamma$-cyclodextrins ( $\alpha$-CD is a six-unit oligosaccharide with a ring diameter approximately $5 \AA$ ). The oxygen-rich structure of the CD has shown to improve the water solubility and stability of graphene nanosheets [46]. Moreover, the increased oxygen content in the interlayer domains has significant advantages as it differs from the oxygen content in the crystal structure of the rGO. The latter results in decreased electronic conductivity due to the decrease in the $\mathrm{sp}^{2}$ hybridized carbon whereas, the former does not alter the electronic conductivity and improves the hydrophilicity of the rGO aerogel and wetting properties of the $\mathrm{Na}^{+}$electrolyte on the rGO aerogel. The focus of this study is to correlate the nano-scale 
heterogeneities and functionality in the structure of rGO-based aerogel electrodes with the electrochemical performance of the sodium-ion batteries. Operando X-ray diffraction (XRD) measurements were performed to investigate if the sodiation of the disordered aerogel electrode occurs through an adsorption or intercalation mechanism.

\section{Experimental}

Graphene oxide (GO) aqueous dispersion was purchased from Graphenea (San Sebastián, Spain). EDA and CD were purchased by Sigma Aldrich (USA) and used as received without further purification. Three-dimensional rGO aerogels were synthesized using the hydrothermal method [47]. EDA or CD (0.1 weight ratio with respect to the GO) was dissolved in a graphene oxide aqueous dispersion (10 mL of a $2 \mathrm{mg} / \mathrm{mL} \mathrm{GO})$, and the mixture was then sonicated for $30 \mathrm{~min}$. The $\mathrm{pH}$ of the rGO-EDA aqueous dispersion was adjusted to 8 using $1 \mathrm{mM} \mathrm{NaOH}$ solution. The $\mathrm{pH}$ of the $\mathrm{rGO}$ and $\mathrm{rGO}-\mathrm{CD}$ dispersions were 2.5. The dispersions were sealed in a $23 \mathrm{~mL}$ Teflon-lined autoclave and heated at $180{ }^{\circ} \mathrm{C}$ for $12 \mathrm{~h}$. Then the autoclave was naturally cooled to room temperature and the hydrogels were retrieved, soaked in ethanol and water to remove the non-bonded EDA or CD. The surface adsorbed water was carefully removed and then the hydrogels were freeze-dried for $24 \mathrm{~h}$ to obtain rGO aerogels. The structure of the synthesized aerogels is shown in Scheme 1. Small-angle neutron scattering (SANS) measurements were performed on the GP-SANS CG-2 beamline at the High Flux Isotope Reactor (HFIR) at Oak Ridge National Laboratory (ORNL) [48]. Samples were sandwiched by two 1-in diameter quartz plates. Three instrument configurations were used to cover the scattering wavevector $q$ range of $0.0015-0.8 \AA^{-1}$. Here, $q=4 \pi \sin \theta / \lambda$ with $\theta$ and $\lambda$ being the half of the scattering angle and neutron beam wavelength, respectively. The low $q$ data were acquired using $19.2 \mathrm{~m}$ sample-to-detector distance (SDD) and $12 \AA$ wavelength with spread $\Delta \lambda / \lambda=13 \%$, the medium $q$ and high $q$ data were acquired with $4.75 \AA$ wavelength $(\Delta \lambda / \lambda=13 \%)$ at two SDDs of $6.8 \mathrm{~m}$ and $1 \mathrm{~m}$, respectively. All the measurements were performed at ambient conditions. The obtained two-dimensional (2D) scattering images were corrected for empty cell, instrument background, transmission, thickness, and detector sensitivity prior to being azimuthally averaged to one-dimensional (1D) curves as a function of wave vector of $q$. A secondary standard sample (porous silica) was used to place the scattering intensity at the absolute scale.

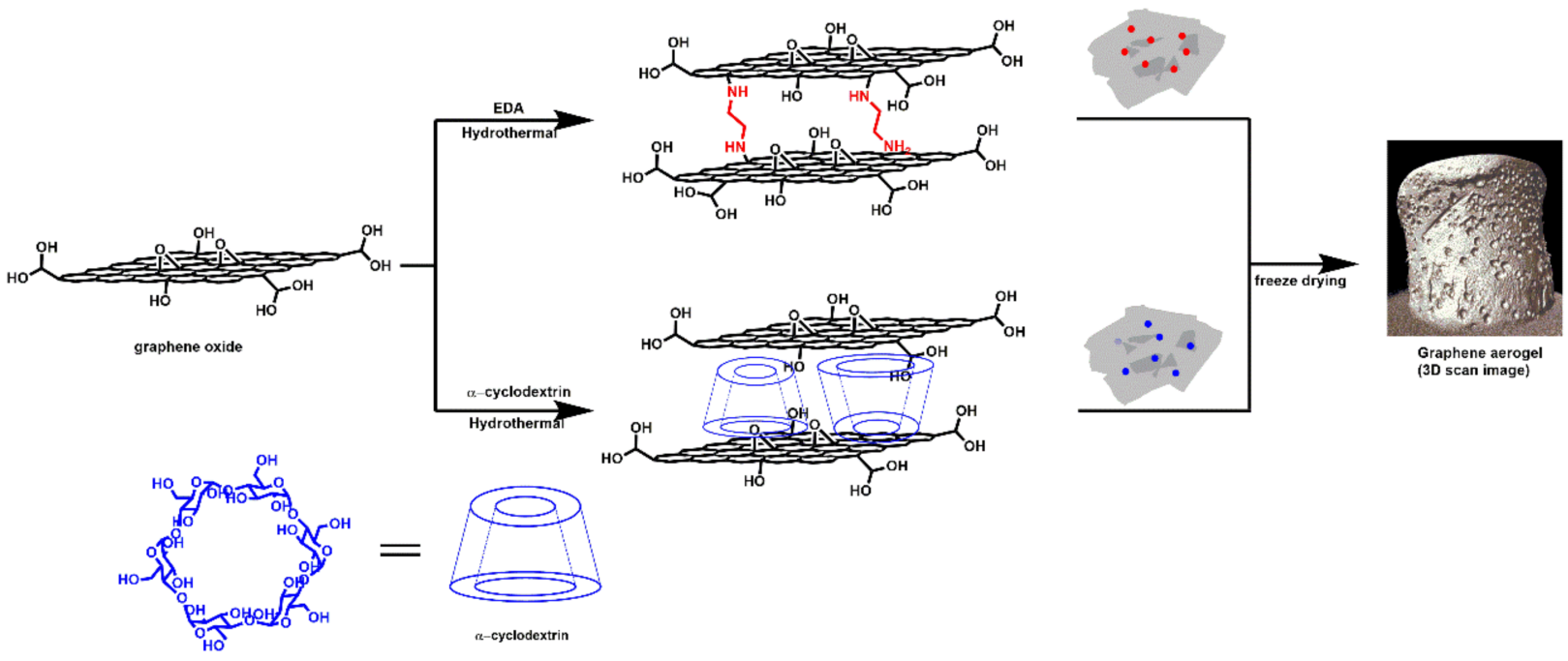

Scheme 1. Graphical illustration of the ethylene diamine and $\alpha$-cyclodextrin modified aerogels. The hydrothermal method was used for the synthesis of the aerogels. The 3D scan image of the aerogel was obtained using X-ray tomography measurements. 
CR2032 coin cells were assembled with the aerogels (pristine, CD, and EDA) as the free-standing positive electrodes and sodium metal as the negative and reference electrode. The assembly of the coin cells was performed in an argon-filled glovebox. The free-standing electrodes were cut into individual circular pieces with average masses approximately $3 \mathrm{mg}$ and $8 \mathrm{~mm}$ diameter. The positive and negative electrodes were electrically separated with a glass fiber separator (Whatman GF/F). The electrolyte used was a $1 \mathrm{M} \mathrm{NaClO} 4$ dissolved in propylene carbonate (PC) (Sigma-Aldrich) with 5 vol.\% fluoroethylene carbonate (FEC) (Sigma-Aldrich) solution. Electrochemical characterization was performed using a VSP potentiostat (Biologic, Seyssinet-Pariset, France). Scanning electron microscopy (SEM), X-ray photoelectron spectroscopy (XPS), and XRD measurements were performed using a Merlin VP SEM/STEM (Zeiss, Oberkochen, Germany) a Model K-Alpha (Thermo Scientific, Waltham, MA, USA) and a X'pert Pro MPD (Malvern Panalytical, Malvern, United Kingdom), respectively. Rheology measurements on the synthesized rGO aerogels were carried out on a Discovery Hybrid Rheometer (DHR-3, TA Instruments, New Castle, DE, USA. The diameter of the disks was $8 \mathrm{~mm}$. Oscillatory frequency sweeps tests were conducted at a preset strain of $0.1 \%$ to measure the storage modulus, and loss modulus over a frequency range from 0.1 to $100 \mathrm{rad} / \mathrm{s}$ at $25^{\circ} \mathrm{C}$. Oscillatory strain sweep tests were conducted from 0.1 to $20 \%$ at an angular frequency of $10 \mathrm{rad} / \mathrm{s}$.

A commercial electrochemical cell (shown in Figure S9) was used to perform operando XRD measurements. The cell consisted of a stainless-steel stub on which the Na metal, a glassy fiber separator and the aerogel sample were mounted. An Al mesh that allows contact with the positive pin that connects to the potentiostat was placed on top of the rGO sample. A $7 \mu \mathrm{m}$ thick Kapton film was placed between the Al mesh and the Be window to avoid redox reaction with the Be. The electrochemical cell was sealed by placing a stainless-steel plate with a rectangular opening on the top via an O-ring. XRD patterns were measured every $30 \mathrm{~min}$ during the charging/discharging of the aerogel based half-cell [49].

\section{Results and Discussion}

The microstructure of the hydrothermally assembled graphene aerogels is shown in the SEM images presented in Figure 1. The pristine aerogel as well as the functionalized aerogels exhibit foam-like, porous structures with a broad pore size distribution. The size of the large pores is several micrometers whereas, the smaller pores have sub-micrometer size. The walls of the pore channels are made of assembled rGO layers. The interconnected multi-sized channels can provide a highly porous electrode scaffold that can accommodate the $\mathrm{NaClO}_{4} / \mathrm{PC}$ electrolyte and the $\mathrm{Na}^{+}$ions. The assembled rGO layers can facilitate additional adsorption sites for the $\mathrm{Na}^{+}$ions. The structure of the assembled layers is dependent on the surface functionality and the spatial heterogeneities that are formed during the assembly process. 

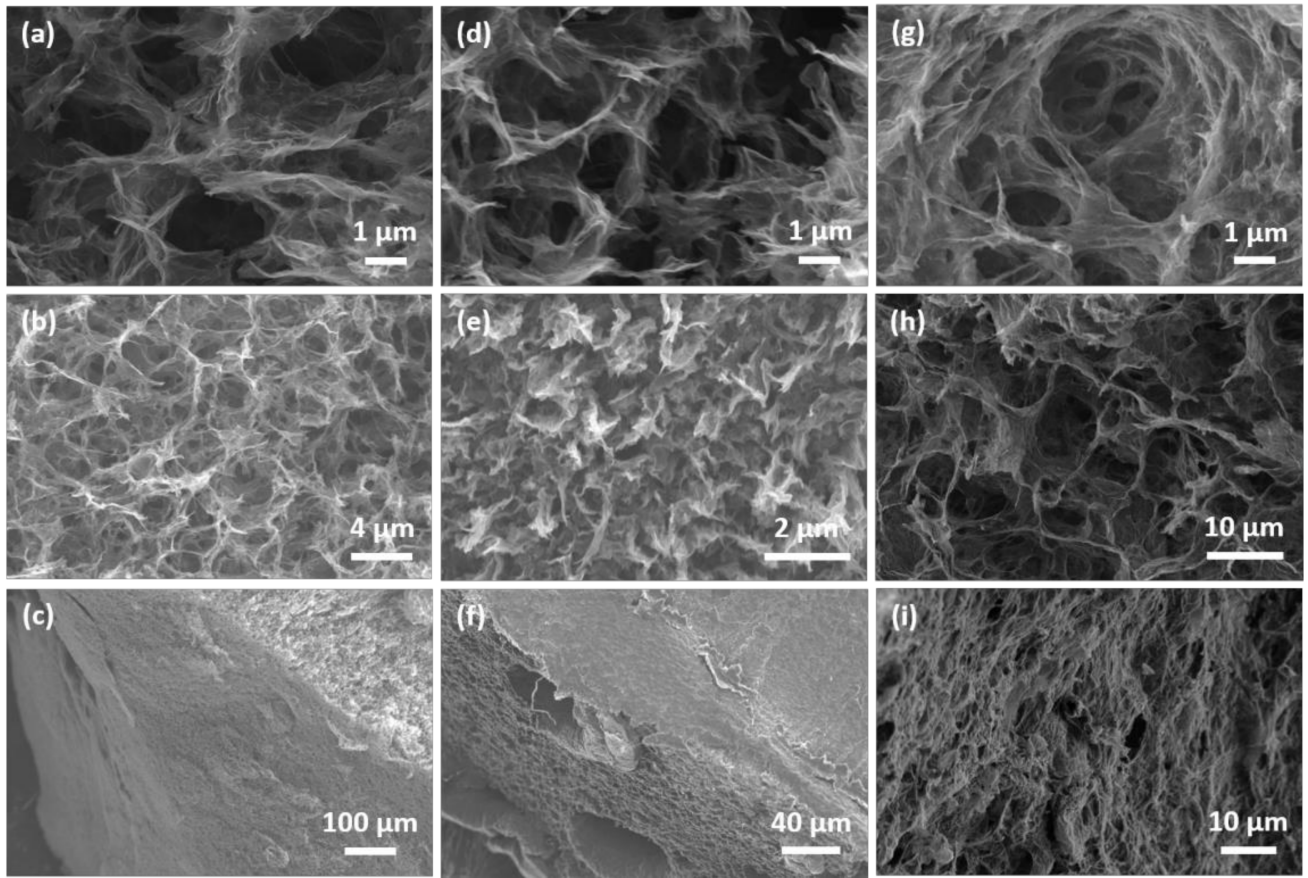

Figure 1. SEM images of the reduced graphene oxide aerogel and of the ethylene diamine and $\alpha-$ cyclodextrin modified aerogels at different areas and several magnifications $(\mathbf{a}-\mathbf{c})$ rGO, $(\mathbf{d}-\mathbf{f})$ rGO-CD, and $(\mathbf{g}-\mathbf{i})$ rGO-EDA aerogels. The areas of the aerogels that were used for the SEM imaging are $(\mathbf{a}, \mathbf{d}, \mathbf{g})$ top view, $(\mathbf{b}, \mathbf{e}, \mathbf{h})$ side view, and $(\mathbf{c}, \mathbf{f}, \mathbf{i})$ cross-sectional view.

The XPS core level spectra for the C 1s, O 1s, and N 1s and the atomic percent of the element groups according to the fitting analysis are shown in Figure 2 and in Table 1, respectively. According to the $\mathrm{C} 1 \mathrm{~s}$ spectra, $\mathrm{C}-\mathrm{C}$ is the primary bonding on the surface of the aerogels (a combination of $\mathrm{sp}^{2}$ and $\mathrm{sp}^{3}$ ). $\mathrm{C}-\mathrm{O}, \mathrm{C}=\mathrm{O}$, and $\mathrm{O}=\mathrm{C}-\mathrm{O}$ features are also marked on the $\mathrm{C} 1$ s spectra. The $\mathrm{O} 1$ s spectra are a combination of $\mathrm{O}-\mathrm{C}$ bonds and $\mathrm{O}=\mathrm{C}$ bonds. The concentration of the $\mathrm{OH}$ groups due to the adsorbed water is not significant. The survey spectra and the element composition of the aerogels are shown in Figure S1 in the Supplementary Materials. The carbon and oxygen content of the pristine GO (prior to the hydrothermal reaction) were 68.1 and 29.8 at.\%, respectively. During the hydrothermal reaction, water molecules were subtracted from the assembled GO stack resulting in the regaining of the pi-conjugation [35,50-52]. The surface functionalization has also shown to contribute to the oxygen reduction $[53,54]$. The $\mathrm{C}$ and $\mathrm{O}$ contents of the rGO aerogel were 87.5 and 11.8 at.\%, respectively. Similar oxygen reduction levels were measured for the functionalized aerogels. The oxygen content of the rGO-CD aerogel was slightly higher (15.0 at.\%) due to the oxygen-rich cyclodextrin groups whereas, the lowest oxygen content was measured for the rGO-EDA aerogel (9.0 at.\%) due to the lack of oxygens in the ethylenediamine. Although the reduced aerogels have significantly lower oxygen content compared to the pristine GO, the reduction process was only partial and did not completely remove the oxygen from the surface of the rGO. The measured atomic percent values of the oxygen are between the respective values for the GO and graphene. For comparison, the survey spectra and the $\mathrm{C} 1 \mathrm{~s}$ and $\mathrm{O} 1 \mathrm{~s}$ core level spectra along with the functional group content for the exfoliated graphite as well as for a graphene powder, are shown in the Supplementary Materials (Figures S4-S6). The oxygen content for the graphene and exfoliated graphite is 3.8 and 1.2 at.\%, respectively. The intermediate oxygen content values for the rGO aerogels impart them with unique surface properties. The increased pi-conjugated bonds enhance the electronic conductivity of the aerogel scaffolds. The moderate content of the oxygen groups reduces the hydrophobicity of the carbon scaffolds and results in better wetting properties of the electrolyte and thus to a better distribution of 
the $\mathrm{Na}^{+}$in the electrode structure [51]. Moreover, an increase in the d-spacing of the rGO layers and a better adsorption of the $\mathrm{Na}^{+}$is expected due to the oxygenated $\mathrm{C}-\mathrm{O}, \mathrm{C}=\mathrm{O}$, and $\mathrm{O}=\mathrm{C}-\mathrm{O}$ groups. Significant pyridinic/pyridinium-like nitrogen bonding (pyridinium is a protonated form of pyridine) was measured in the $\mathrm{N}$ 1s spectra of the rGO-EDA aerogel (13.1 at.\%) due to the ethylene diamine functionality.
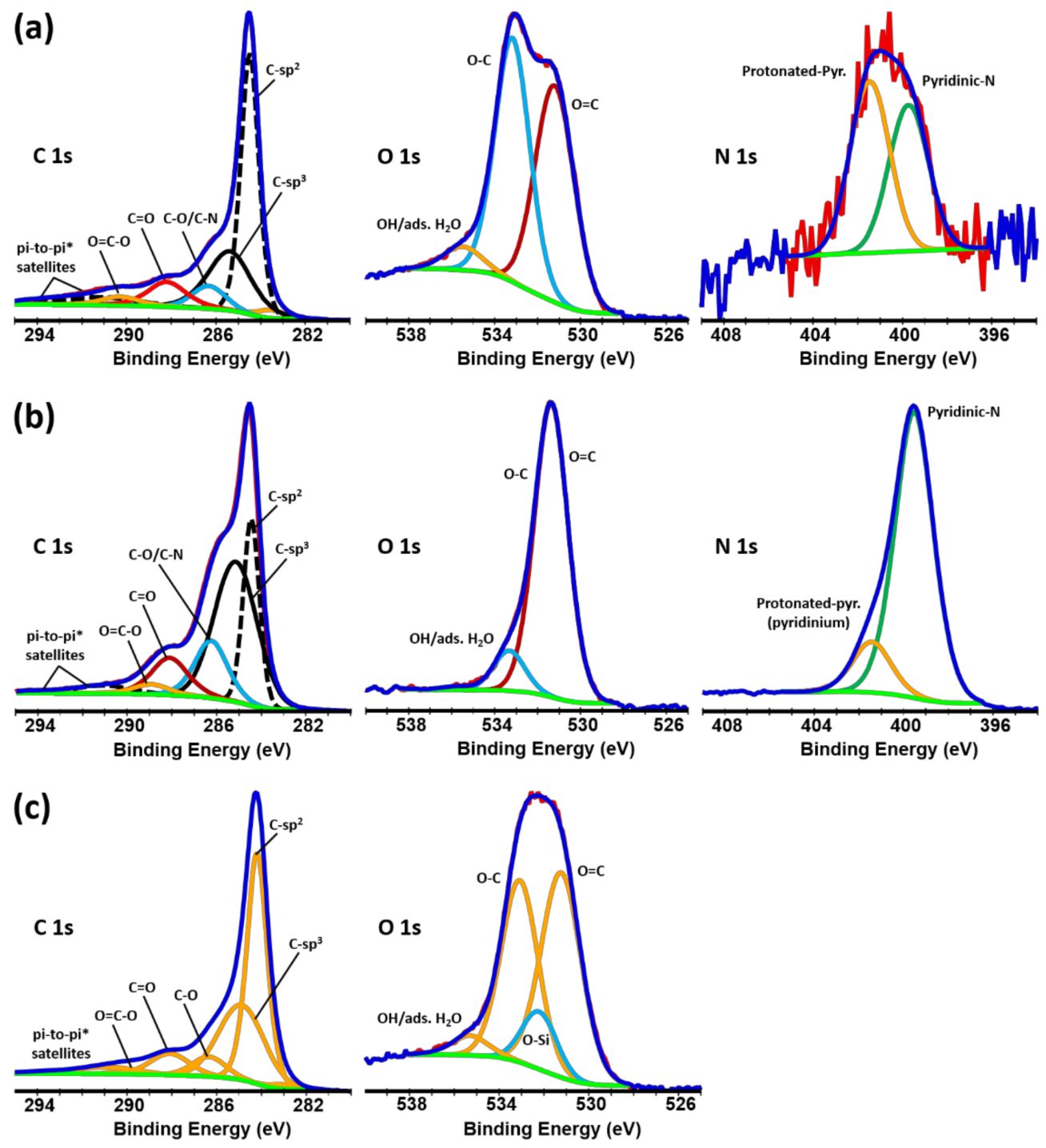

Figure 2. $\mathrm{C} 1 \mathrm{~s}, \mathrm{O} 1 \mathrm{~s}$, and $\mathrm{N} 1 \mathrm{~s}$ core level spectra and individual peak fitting for the (a) rGO, (b) rGO-EDA, and (c) rGO-CD aerogels. 
Table 1. Quantitative analysis of the overall surface composition for the rGO, rGO-EDA, and rGO-CD aerogels according to the core level spectra fitting in Figure 2.

\begin{tabular}{|c|c|c|c|c|c|c|c|c|}
\hline \multicolumn{3}{|c|}{ rGO } & \multicolumn{3}{|c|}{ rGO-EDA } & \multicolumn{3}{|c|}{ rGO-CD } \\
\hline Name & At. $\%$ & B.E. $(\mathrm{eV})$ & Name & At. $\%$ & B.E. $(\mathrm{eV})$ & Name & At. $\%$ & B.E. $(\mathrm{eV})$ \\
\hline $\mathrm{C}\left(\mathrm{sp}^{2}\right)$ & 47.6 & 284.5 & $\mathrm{C}\left(\mathrm{sp}^{2}\right)$ & 21.2 & 284.5 & $\mathrm{C}\left(\mathrm{sp}^{2}\right)$ & 43.8 & 284.5 \\
\hline$C\left(\mathrm{sp}^{3}\right)$ & 21.4 & 285.4 & $C\left(\mathrm{sp}^{3}\right)$ & 34.6 & 285.2 & $\mathrm{C}\left(\mathrm{sp}^{3}\right)$ & 27.3 & 285.2 \\
\hline $\mathrm{C}-\mathrm{O}$ & 6.0 & 286.3 & $\mathrm{C}-\mathrm{O}$ & 11.2 & 286.3 & $\mathrm{C}-\mathrm{O}$ & 4.8 & 286.7 \\
\hline $\mathrm{C}=\mathrm{O}$ & 8.5 & 288.2 & $\mathrm{C}=\mathrm{O}$ & 8.2 & 288.2 & $\mathrm{C}=\mathrm{O}$ & 6.2 & 288.4 \\
\hline $\mathrm{O}=\mathrm{C}-\mathrm{O}$ & 4.0 & 290.3 & $\mathrm{O}=\mathrm{C}-\mathrm{O}$ & 2.1 & 289.0 & $\mathrm{O}=\mathrm{C}-\mathrm{O}$ & 1.4 & 290.1 \\
\hline $\mathrm{N}^{+}$ & 0.3 & 401.5 & $\mathrm{~N}^{+}$ & 2.0 & 401.4 & $\mathrm{O}=\mathrm{C}$ & 7.7 & 531.6 \\
\hline \multirow[t]{2}{*}{ N-pyr } & 0.3 & 399.7 & N-pyr & 11.1 & 399.5 & $\mathrm{O}-\mathrm{Si}$ & 1.3 & 532.5 \\
\hline & & & & & & $\mathrm{O}-\mathrm{C}$ & 5.5 & 533.4 \\
\hline $\mathrm{O}-\mathrm{C}$ & 5.7 & 533.2 & $\mathrm{O}-\mathrm{C}$ & 1.0 & 533.3 & $-\mathrm{OH}$ & 0.5 & 535.6 \\
\hline $\mathrm{O}=\mathrm{C}-\mathrm{O}$ & 5.5 & 531.2 & $\mathrm{O}=\mathrm{C}-\mathrm{O}$ & 7.9 & 531.4 & & & \\
\hline \multirow[t]{2}{*}{$-\mathrm{OH}$} & 0.6 & 535.5 & $-\mathrm{OH}$ & 0.1 & 535.8 & $\mathrm{Si}$ & 1.3 & 101.7 \\
\hline & & & & & & $\mathrm{Na}$ & 0.2 & 1071.6 \\
\hline \multirow[t]{3}{*}{ S } & 0.1 & 168.2 & $S$ & 0.1 & 168.2 & & & \\
\hline & & & $\mathrm{Si}$ & 0.1 & 102.1 & & & \\
\hline & & & $\mathrm{Na}$ & 0.4 & 1071.4 & & & \\
\hline
\end{tabular}

The viscoelastic properties of the aerogels were evaluated using oscillatory frequency sweeps. The frequency dependence of the storage (elastic) and loss (viscous) modulus are shown in Figure 3. The storage modulus values of the rGO and rGO-CD aerogels are comparable. At $0.1 \mathrm{rad} / \mathrm{s}$ both values are approximately $0.3 \mathrm{MPa}$. Similar values have been reported in the literature for graphene hydrogels [35]. The storage modulus value of the rGO-EDA aerogel showed a two-fold increase ( $0.8 \mathrm{MPa})$ compared to the respective values of the pristine and cyclodextrin-modified aerogels. This increase can be attributed to the crosslinking of the rGO layers through the diamine groups.
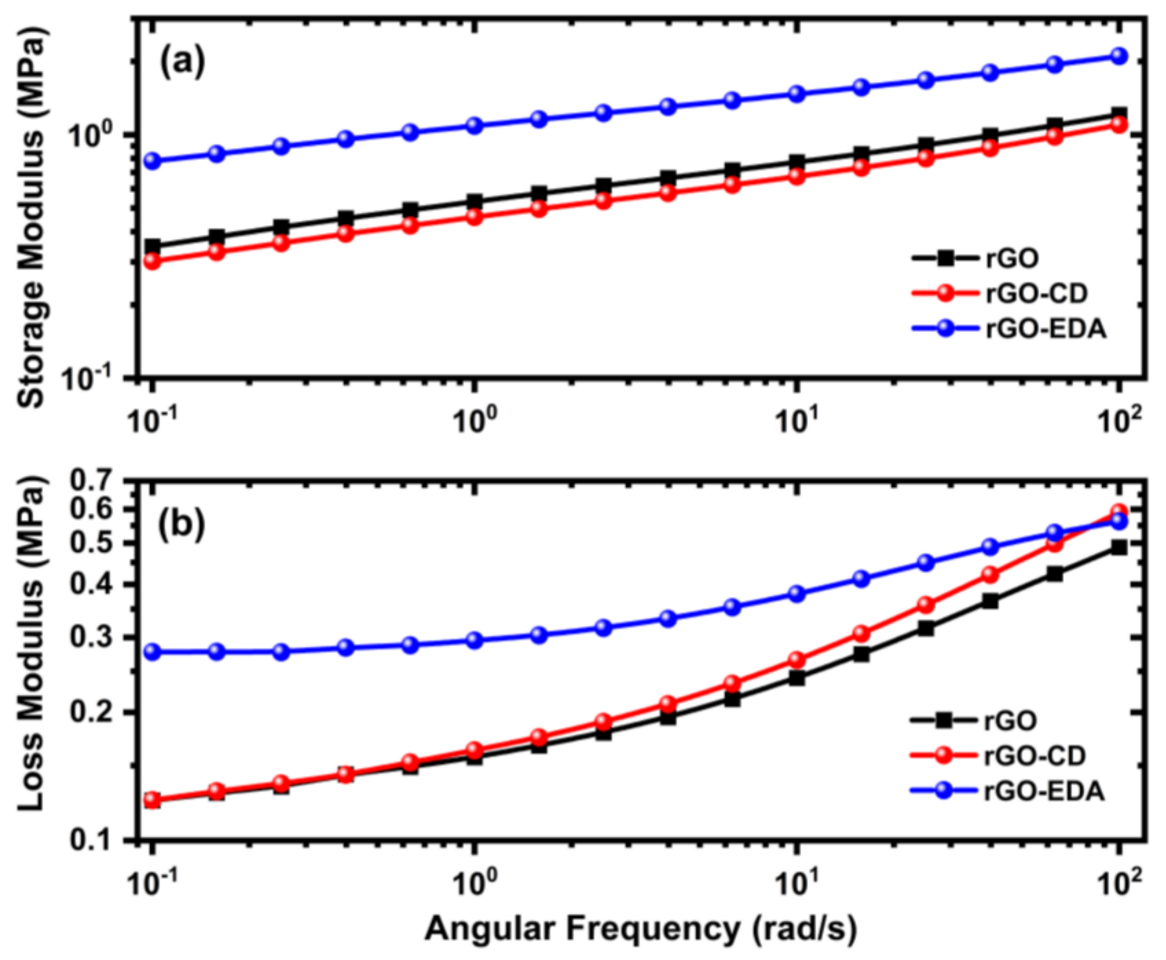

Figure 3. Rheological properties of the synthesized rGO and rGO functionalized aerogels. (a) The storage and (b) loss modulus were measured from oscillatory frequency sweeps. 
The XRD patterns of the rGO-based aerogels are shown in Figure 4. For comparison, the diffraction pattern of the unmodified GO that was used in the hydrothermal reaction is also presented. The $2 \theta$ value of the diffraction peak for the GO is positioned at of $10.4^{\circ}$ and corresponds to an interlayer spacing $\left(d_{\mathrm{sp}}\right)$ of $0.85 \mathrm{~nm}$, where $d_{\mathrm{sp}}=\lambda / 2 \sin \theta$ with $\lambda$ being the wavelength of X-ray beam. The X-ray beam wavelength was $\lambda=1.5418 \AA, \mathrm{Cu}$ $K \alpha$ radiation. The typical interlayer spacing of the natural graphite for the (002) diffraction peak is approximately $0.34 \mathrm{~nm}\left(2 \theta=26.4^{\circ}\right)[35,55]$. The higher interlayer spacing of the GO is attributed to the repulsive forces between the basal planes due the presence of oxygen groups. The aerogels do not exhibit the characteristic diffraction peak for the GO. The $2 \theta$ values for the diffraction peaks of the aerogels are positioned at higher values compared to the GO diffraction peak. The shifting towards higher $2 \theta$ values can be attributed to the hydrothermally induced oxygen reduction and the resulting decrease of the interlayer spacing. The latter is $0.37 \mathrm{~nm}\left(2 \theta=24.1^{\circ}\right)$ for the rGO aerogel, which is in good agreement with values reported in literature for hydrothermally reduced graphene oxide $[35,55]$. The interlayer spacings of the rGO-EDA and rGO-CD aerogels are $0.36 \mathrm{~nm}\left(2 \theta=24.5^{\circ}\right)$ and 0.34 $\mathrm{nm}\left(2 \theta=26.2^{\circ}\right)$, respectively. These values approach the $2 \theta$ value of the natural graphite however, the diffraction peaks are very broad compared to the very narrow diffraction peak of the natural graphite (FWHM approximately 0.2 degrees [56]) as well as to the diffraction peak of the GO. The broadening of the diffraction peaks indicates a disordered stacking of the assembled rGO layers [35,55]. This structural disorder is more evident in the surface modified aerogels and especially in the rGO-CD that is characterized by an asymmetrical broadening of the diffraction peak. This behavior can be associated with the intricate ring-type structure of the cyclodextrin molecules that resulted in a more anisotropic assembly mechanism. The introduced functionalities prevent the ordered assembly of the reduced oxide layers and introduce structural heterogeneities that can provide additional adsorption sites for the sodium ions. The XRD results are in good agreement with the BET measurement results (Figure S3 in the Supplementary Materials). The half pore width and the pore volume distributions show a clear shift towards higher values for the rGO-CD aerogel in the 30 to $80 \AA$ range.

The SANS 1D spectra of the aerogels are shown in Figure 5. At wavevector $(q)$ values higher than $0.3 \AA^{-1}$ different scattering intensities can be seen for the three aerogels. The PRINSAS software was used to analyze the data assuming that the pores are spherical (there is no analytical function to fit scattering from slit-like pores with polydisperse size distribution [57]). The cut-off pore size was $10 \AA$. The volume-weighted pore size distributions for all three samples are displayed in the inset plot in Figure 5. All aerogels show significant number of pore formation between 10 to $80 \AA$ and a peak around $48 \AA$ that is in good agreement with the BET and XRD results. The rGO-CD and rGO-EDA aerogels are characterized by more pronounced pore structures with size below $20 \AA$ compared to the rGO aerogel. 


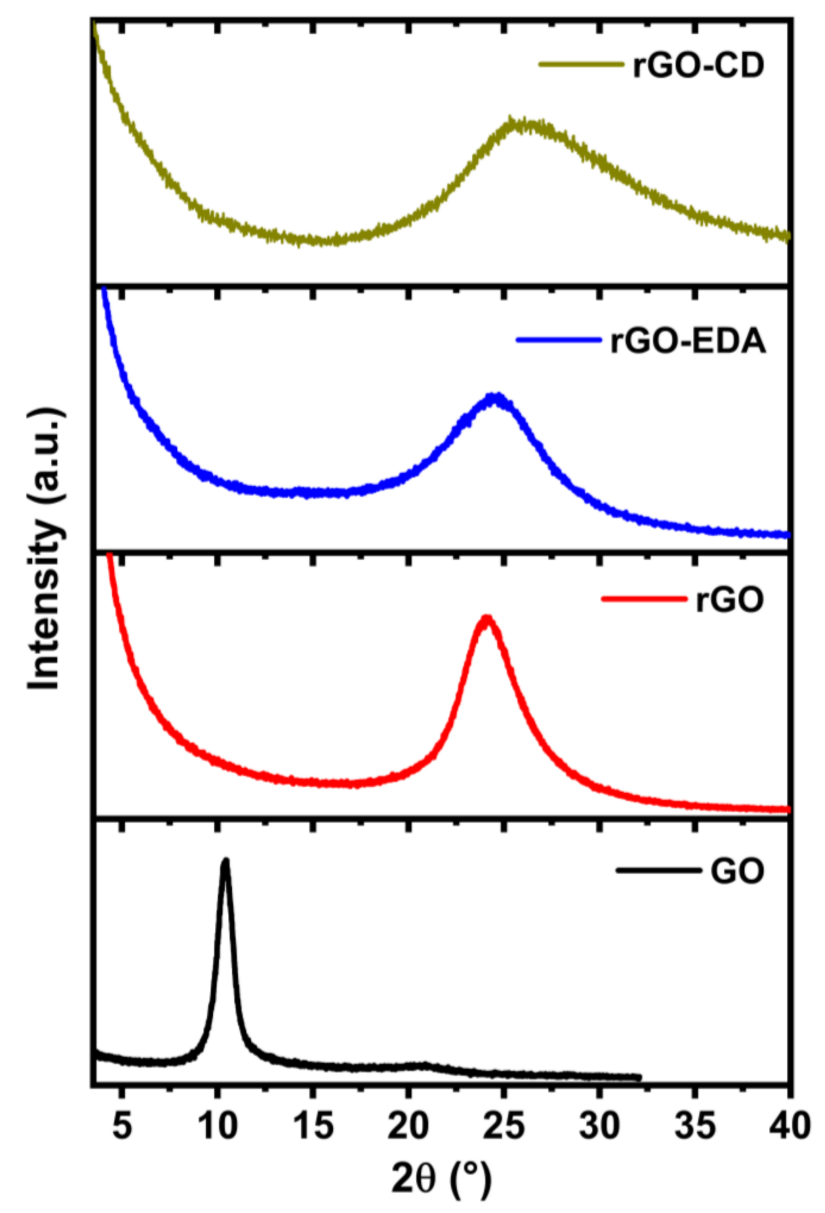

Figure 4. XRD patterns for the GO, rGO and the surface modified rGO-EDA and rGO-CD aerogels.

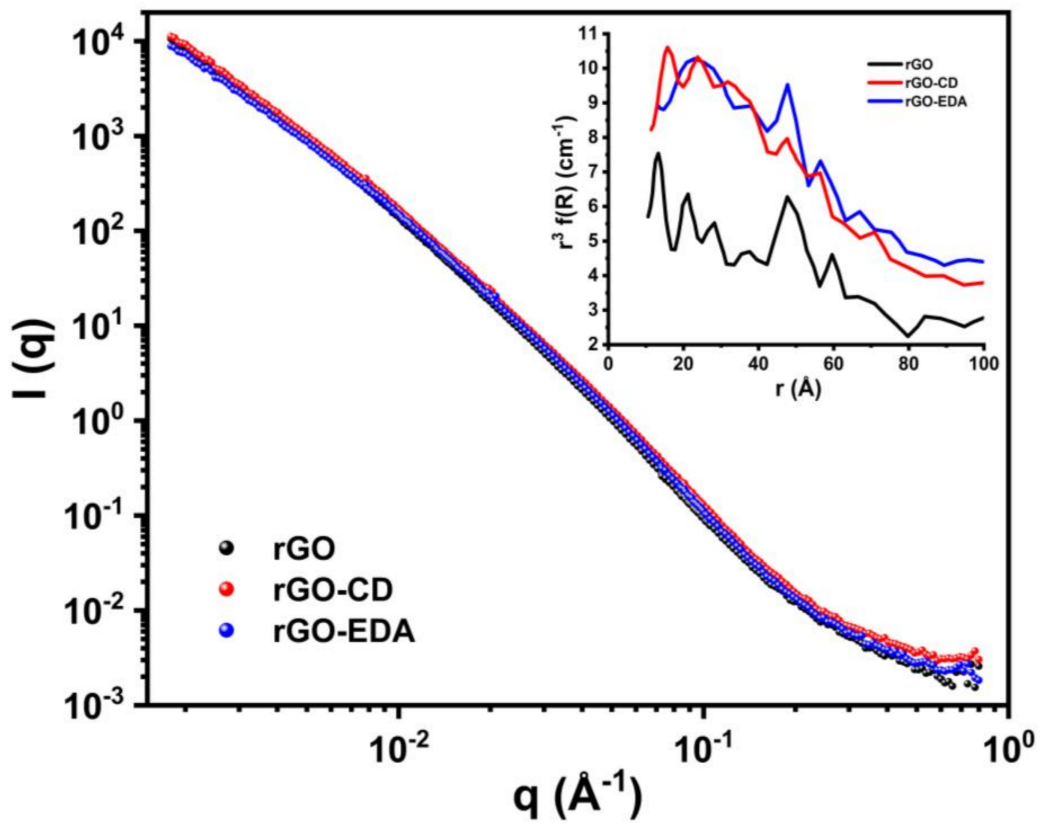

Figure 5. SANS measurements for the GO, and the rGO, rGO-EDA and rGO-CD aerogels. The inset plot shows the pore size distribution of the aerogels.

Characteristic charge and discharge voltage profiles of the assembled cells are shown in Figure 6. The high-capacity values during the first cycles are associated with the formation 
of the solid electrolyte interphase (SEI) and such high values are typical for porous electrode structures with large surface area $[43,44]$. The SEI formation is also shown in the cyclic voltammetry (CV) measurements in Figure S8 (Supplementary Materials). The SEI for the rGO-EDA and rGO-CD is formed at higher potential values compared to the pristine rGO. This is in good agreement with the charge and discharge voltage profiles in Figure 6a. The electrolyte reduction (decomposition) in the CV measurements of the rGO is present in all measured (10) cycles indicating a less stable SEI compared to the SEI in the modified aerogels. The electrolyte reduction in the modified aerogels is present only in the first cycle. The rate performance of the aerogels is summarized in Figure 7. The cycling stability of the pristine unmodified rGO aerogel was poor. The cells failed after 20 cycles at $0.05 \mathrm{C}$. This behavior can be attributed to the electrolyte decomposition [58] that is evident in the CV testing results in Figure S8. The cyclability of the surface modified aerogels was significantly improved. The rGO-CD exhibited the highest capacity values at 0.05 and $0.1 \mathrm{C}$ rates. This can be related to the more disordered structure of the assembled rGO layers (the asymmetric broadening of the XRD pattern for the rGO-CD indicates a broad distribution in the interlayer spacing) as well as to the higher oxygen content of the CD functionality. The amine modified rGO-EDA aerogel, although it demonstrated lower capacity values at 0.05 and $0.1 \mathrm{C}$ rates, its cycling performance was more stable and the trend in the capacity and Coulombic efficiency values was consistent with less scattering over the measured cycles. The introduced structural heterogeneities enhanced the rate performance with the more anisotropic assembled structure resulting in higher capacity values. Interestingly, at the highest measured rate $(1 \mathrm{C})$ the capacity values of the two surface modified aerogels coincide. This behavior can be attributed to the slow diffusion mechanism of the $\mathrm{Na}^{+}$ions. At low charge and discharge rates there is sufficient time for the $\mathrm{Na}^{+}$ions to occupy more sites resulting in a better sodiation and desodiation of the available sites in the cathode. At a higher rate, not all available sites for the adsorption of the $\mathrm{Na}^{+}$ions can be utilized, and the rate performance of the surface modified aerogels is similar.

The operando XRD patterns of the rGO-CD aerogel at $0.1 \mathrm{C}$ rate are shown in Figure 8. The characteristic broad peak at $2 \theta=26^{\circ}$ does not shift during the charge and discharge cycling indicating the absence of $\mathrm{Na}^{+}$intercalation between the assembled rGO-CD layers. The experimental results are in good agreement with first-principles calculations indicating that the $\mathrm{Na}^{+}$intercalation in graphite structures is not energetically favorable because the weak bond between the sodium alkali metal and the carbon atoms results in a positive formation energy for the intercalated structures $[23,24]$. According to the operando XRD measurements the mechanism responsible for the sodiation of the aerogels is the adsorption of the $\mathrm{Na}^{+}$ions on the rGO surface. The disordered assembly of the functionalized rGO layers increased the porosity of the rGO-CD and rGO-EDA aerogels (SANS measurements in Figure 5) compared to the non-functionalized rGO aerogel. The more porous rGO-CD aerogel exhibited the highest capacity values during the electrochemical cycling. 

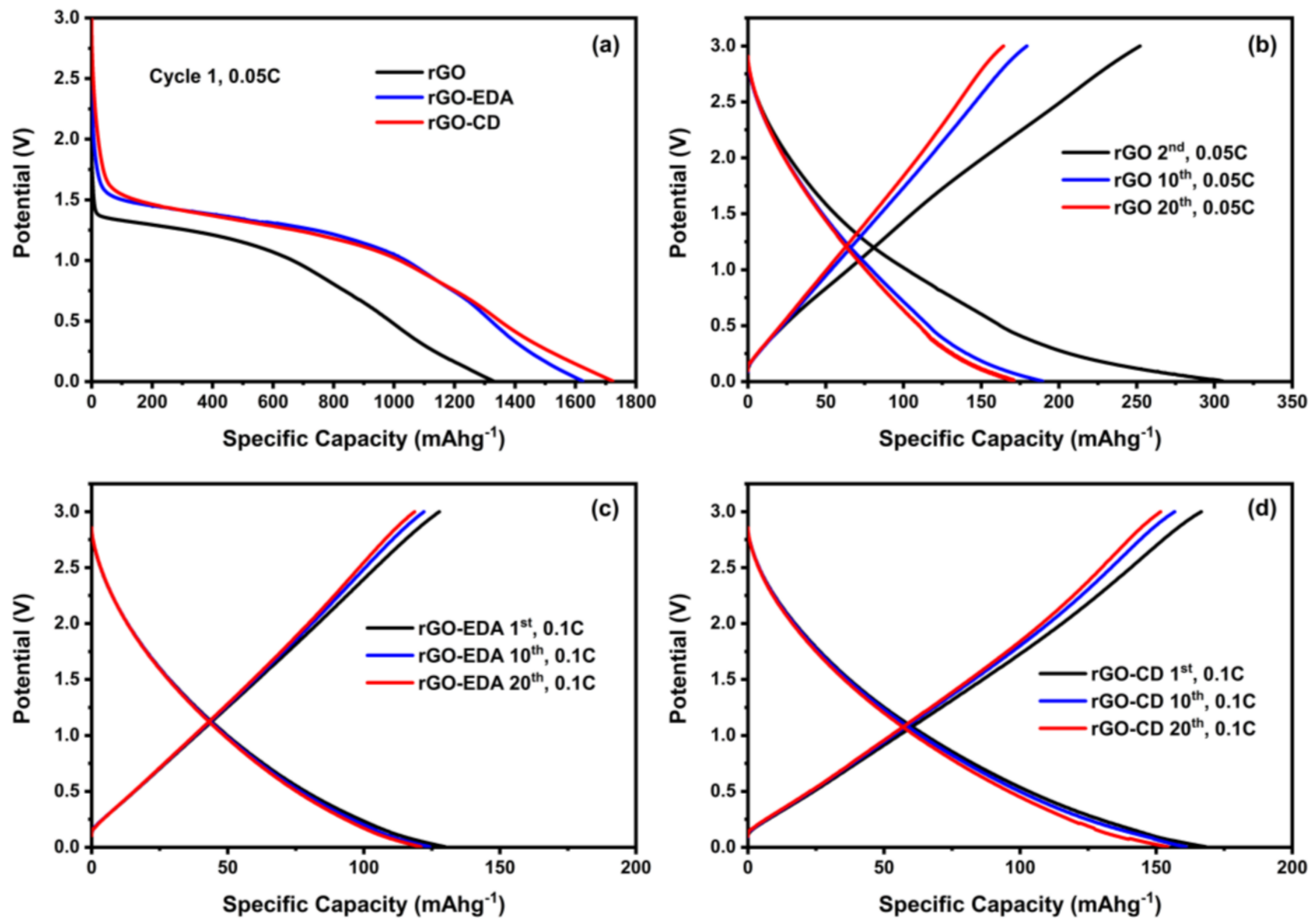

Figure 6. Charge and discharge profiles of the rGO and rGO modified aerogels. (a) Formation of the SEI during the 1st discharge cycle. Voltage profiles at several cycling rates (b) rGO at $0.05 \mathrm{C}$, (c) rGO-EDA at $0.1 \mathrm{C},(\mathbf{d}) \mathrm{rGO}-\mathrm{CD}$ at $0.1 \mathrm{C}$ rate.

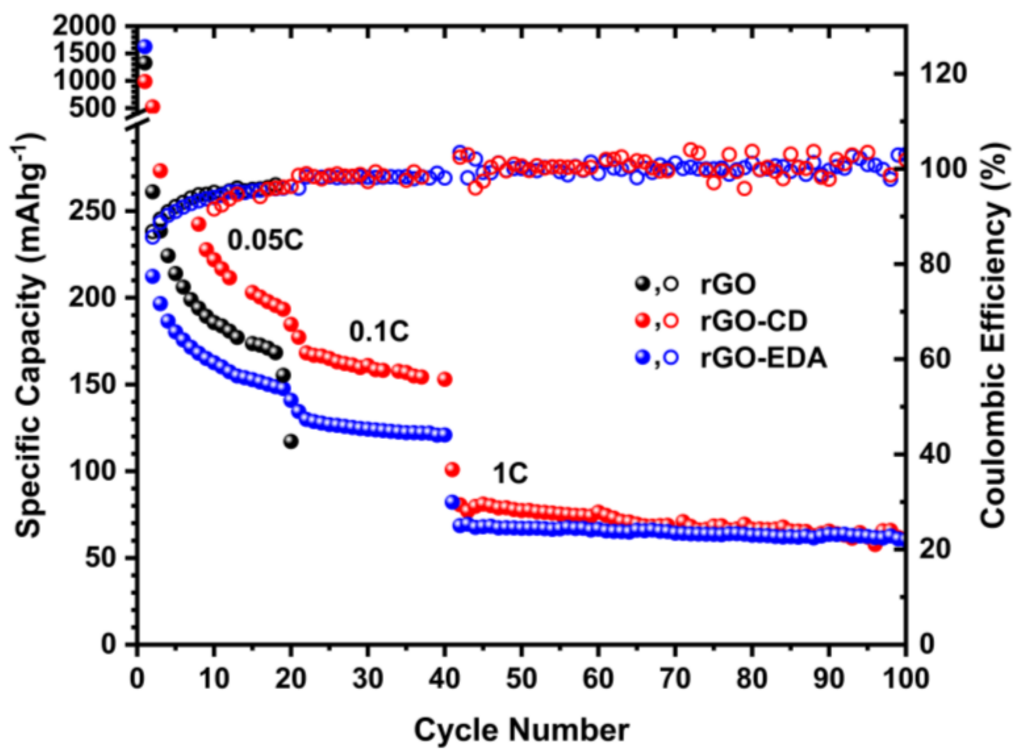

Figure 7. Discharge capacity of the rGO and rGO modified aerogels at $0.05,0.1$, and $1 \mathrm{C}$ rates. 


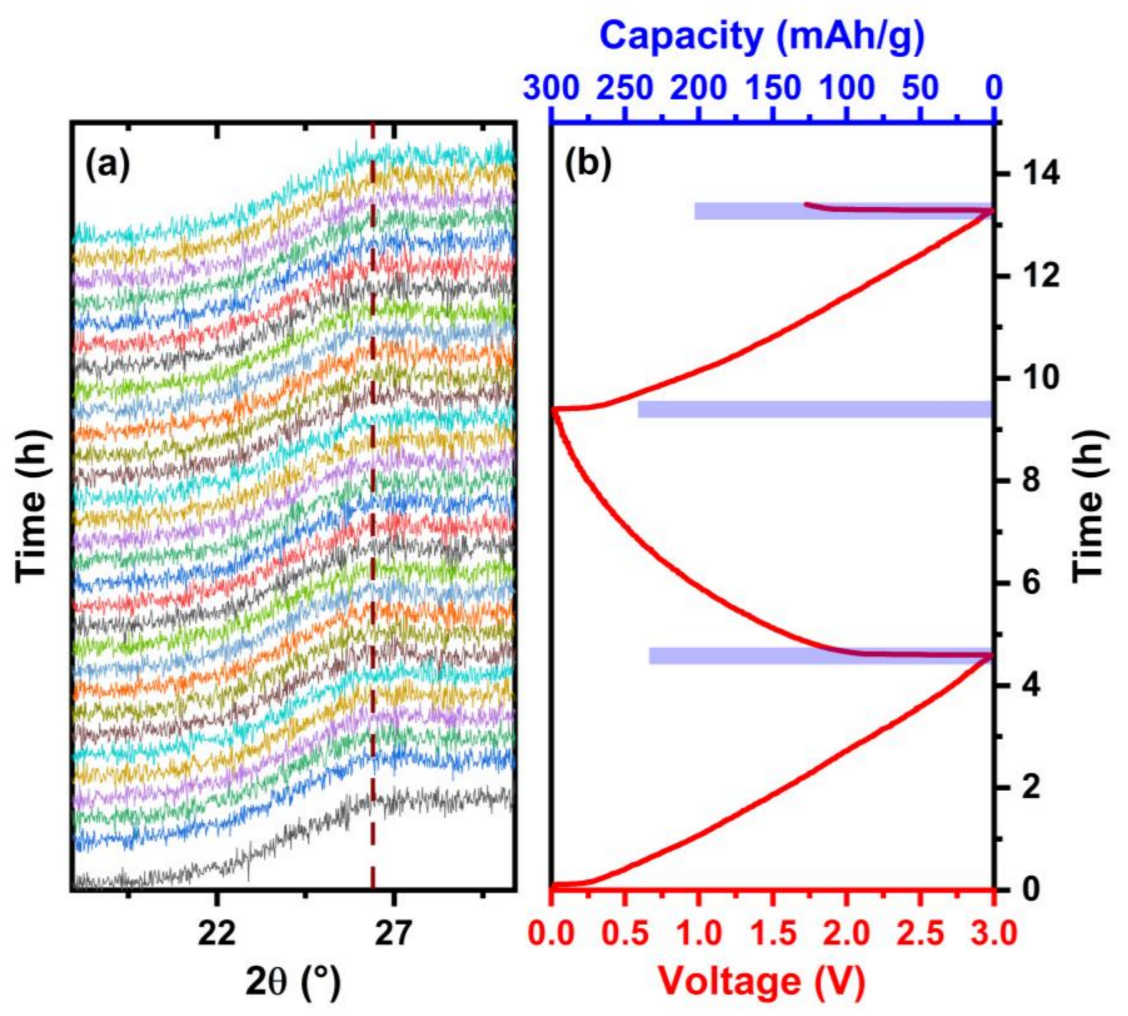

Figure 8. XRD patterns obtained during the charge and discharge of the cell. (a) Operando XRD patterns of the rGO-CD aerogel. The broken line indicates the broad peak at $2 \theta=26^{\circ}$. (b) The corresponding discharge and charge profile at $0.1 \mathrm{C}$ rate. The capacity values are shown in the bar plot.

\section{Conclusions}

Self-assembled rGO aerogel electrodes with functionalization-driven disordered stacking were synthesized. The EDA and CD surface functionalities covalently interconnected the rGO layers and hindered their ordered assembly during the hydrothermal reaction. The electrochemical performance of sodium-ion battery cells based on the synthesized aerogels was evaluated at several cycling rates and was found to depend on the structural heterogeneities of the electrodes. The rGO-CD exhibited the most disordered structure. XRD measurements showed an asymmetric broadening of the diffraction pattern indicating a broad distribution in the interlayer spacing. The latter resulted in the formation of more pronounced nano-pore sizes that was also confirmed by SANS and BET measurements. The formation of pores with a broad size distribution that can accommodate $\mathrm{Na}^{+}$ions was found to improve the cycling performance at 0.05 and $0.1 \mathrm{C}$ rates. A possible improvement in the wettability between the $\mathrm{Na}^{+}$electrolyte and the $\mathrm{rGO}-\mathrm{CD}$ aerogel, due to the high oxygen content of the CD functionality, may also have synergistically contributed to the better electrochemical performance of the rGO-CD. An intercalation mechanism of the $\mathrm{Na}^{+}$ ions in the layered assemblies of the rGO-CD aerogel was not evident in the operando XRD measurements. The sodiation of the aerogels during the electrochemical cycling occurs through an adsorption mechanism of the $\mathrm{Na}^{+}$ions on the surface of the porous rGO assemblies.

Supplementary Materials: XPS spectra, additional rheological properties, BET measurements, Auger spectra and cyclic voltammetry measurements are provided online at: https://www.mdpi.com/ article/10.3390/batteries8020012/s1.

Author Contributions: Conceptualization, J.P., G.P.; experimental data and analysis, J.P., J.S., C.J.J., L.H., H.M.M.III, J.L., J.K.K., N.A.N., G.P.; writing—review and editing, J.P., J.S., C.J.J., L.H., H.M.M.III, 
J.L., J.K.K., N.A.N., G.P.; supervision, G.P. All authors have read and agreed to the published version of the manuscript.

Funding: This research at Oak Ridge National Laboratory, managed by UT Battelle, LLC, for the U.S. Department of Energy (DOE) under contract DE-AC05-00OR22725, was sponsored by Office of Electricity. J.P. was supported by Laboratory Directed Research and Development Program at Oak Ridge National Laboratory.

Institutional Review Board Statement: Not applicable.

Informed Consent Statement: Not applicable.

Data Availability Statement: Not applicable.

Acknowledgments: The SEM and XRD characterization were conducted at the Center for Nanophase Materials Sciences, which is a DOE Office of Science User Facility. A portion of this research used resources at the High Flux Isotope Reactor, a DOE Office of Science User Facility operated by the Oak Ridge National Laboratory.

Conflicts of Interest: The authors declared no conflicts of interest.

\section{References}

1. Arico, A.S.; Bruce, P.; Scrosati, B.; Tarascon, J.M.; van Schalkwijk, W. Nanostructured materials for advanced energy conversion and storage devices. Nat. Mater. 2005, 4, 366-377. [CrossRef] [PubMed]

2. Lu, L.; Han, X.; Li, J.; Hua, J.; Ouyang, M. A review on the key issues for lithium-ion battery management in electric vehicles. J. Power Sources 2013, 226, 272-288. [CrossRef]

3. Wang, Y.; Liu, B.; Li, Q.; Cartmell, S.; Ferrara, S.; Deng, Z.D.; Xiao, J. Lithium and lithium ion batteries for applications in microelectronic devices: A review. J. Power Sources 2015, 286, 330-345. [CrossRef]

4. Larcher, D.; Tarascon, J.M. Towards greener and more sustainable batteries for electrical energy storage. Nat. Chem. 2015, 7, 19-29. [CrossRef] [PubMed]

5. Li, M.; Lu, J.; Chen, Z.; Amine, K. 30 Years of lithium-ion batteries. Adv. Mater. 2018, 30, 1800561. [CrossRef]

6. Nitta, N.; Wu, F.; Lee, J.T.; Yushin, G. Li-ion battery materials: Present and future. Mater. Today 2015, 18, 252-264. [CrossRef]

7. Manthiram, A. A reflection on lithium-ion battery cathode chemistry. Nat. Commun. 2020, 11, 1550. [CrossRef]

8. Kim, T.; Song, W.; Son, D.Y.; Ono, L.K.; Qi, Y. Lithium-ion batteries: Outlook on present, future, and hybridized technologies. J. Mater. Chem. A 2019, 7, 2942-2964. [CrossRef]

9. Kim, H.J.; Krishna, T.; Zeb, K.; Rajangam, V.; Gopi, C.V.V.M.; Sambasivam, S.; Raghavendra, K.V.G.; Obaidat, I.M. A comprehensive review of Li-ion battery materials and their recycling techniques. Electronics 2020, 9, 1161. [CrossRef]

10. Abraham, K.M. How comparable are sodium-ion batteries to lithium-ion counterparts? ACS Energy Lett. 2020, 5, 3544-3547. [CrossRef]

11. Palomares, V.; Serras, P.; Villaluenga, I.; Hueso, K.B.; Carretero-González, J.; Rojo, T. Na-ion batteries, recent advances and present challenges to become low cost energy storage systems. Energy Environ. Sci. 2012, 5, 5884-5901. [CrossRef]

12. Yabuuchi, N.; Kubota, K.; Dahbi, M.; Komaba, S. Research development on sodium-ion batteries. Chem. Rev. 2014, 114, 11636-11682. [CrossRef] [PubMed]

13. Vaalma, C.; Buchholz, D.; Weil, M.; Passerini, S. A cost and resource analysis of sodium-ion batteries. Nat. Rev. Mater. 2018, 3, 18013. [CrossRef]

14. Nayak, P.K.; Yang, L.; Brehm, W.; Adelhelm, P. From lithium-ion to sodium-ion batteries: Advantages, challenges, and surprises. Angew. Chem. Int. Ed. 2018, 57, 102-120. [CrossRef]

15. Saurel, D.; Orayech, B.; Xiao, B.; Carriazo, D.; Li, X.; Rojo, T. From charge storage mechanism to performance: A roadmap toward high specific energy sodium-ion batteries through carbon anode optimization. Adv. Energy Mater. 2018, 8, 1703268. [CrossRef]

16. Slater, M.D.; Kim, D.; Lee, E.; Johnson, C.S. Sodium-ion batteries. Adv. Funct. Mater. 2013, 23, 947-958. [CrossRef]

17. Chayambuka, K.; Mulder, G.; Danilov, D.L.; Notten, P.H.L. Sodium-ion battery materials and electrochemical properties reviewed. Adv. Energy Mater. 2018, 8, 1800079. [CrossRef]

18. Mohsin, I.U.; Ziebert, C.; Rohde, M.; Seifert, H.J. Thermophysical characterization of a layered $\mathrm{P}_{2}$ type structure $\mathrm{Na}_{0.53} \mathrm{MnO}_{2}$ cathode material for sodium ion batteries. Batteries 2021, 7, 16. [CrossRef]

19. Li, M.; Mullaliu, A.; Passerini, S.; Giorgetti, M. Titanium activation in Prussian blue based electrodes for Na-ion batteries: A synthesis and electrochemical study. Batteries 2021, 7, 5. [CrossRef]

20. Maça, R.R.; Etacheri, V. Effect of vinylene carbonate electrolyte additive on the surface chemistry and pseudocapacitive sodium-ion storage of $\mathrm{TiO}_{2}$ nanosheet anodes. Batteries 2021, 7, 1. [CrossRef]

21. Ford, H.O.; Cui, C.; Schaefer, J.L. Comparison of single-ion conducting polymer gel electrolytes for sodium, potassium, and calcium batteries: Influence of polymer chemistry, cation identity, charge density, and solvent on conductivity. Batteries $2020,6,11$. [CrossRef]

22. Peters, J.F.; Peña Cruz, A.; Weil, M. Exploring the economic potential of sodium-ion batteries. Batteries 2019, 5, 10. [CrossRef] 
23. Nobuhara, K.; Nakayama, H.; Nose, M.; Nakanishi, S.; Iba, H. First-principles study of alkali metal-graphite intercalation compounds. J. Power Sources 2013, 243, 585-587. [CrossRef]

24. Moriwake, H.; Kuwabara, A.; Fisher, C.A.J.; Ikuhara, Y. Why is sodium-intercalated graphite unstable? RSC Adv. 2017, 7 , 36550-36554. [CrossRef]

25. Zhang, W.; Zhang, F.; Ming, F.; Alshareef, H.N. Sodium-ion battery anodes: Status and future trends. EnergyChem $2019,1,100012$. [CrossRef]

26. Chen, M.; Liu, Q.; Wang, S.W.; Wang, E.; Guo, X.; Chou, S.L. High-abundance and low-cost metal-based cathode materials for sodium-ion batteries: Problems, progress, and key technologies. Adv. Energy Mater. 2019, 9, 1803609. [CrossRef]

27. Chen, M.; Hua, W.; Xiao, J.; Cortie, D.; Chen, W.; Wang, E.; Hu, Z.; Gu, Q.; Wang, X.; Indris, S.; et al. NASICON-type air-stable and all-climate cathode for sodium-ion batteries with low cost and high-power density. Nat. Commun. 2019, 10, 1480. [CrossRef]

28. Huang, Y.; Zheng, Y.; Li, X.; Adams, F.; Luo, W.; Huang, Y.; Hu, L. Electrode materials of sodium-ion batteries toward practical application. ACS Energy Lett. 2018, 3, 1604-1612. [CrossRef]

29. Kim, H.; Kim, H.; Ding, Z.; Lee, M.H.; Lim, K.; Yoon, G.; Kang, K. Recent progress in electrode materials for sodium-ion batteries. Adv. Energy Mater. 2016, 6, 1600943. [CrossRef]

30. Fang, Y.; Yu, X.Y.; Lou, X.W. Nanostructured electrode materials for advanced sodium-ion batteries. Matter 2019, 1, 90-114 [CrossRef]

31. Fan, X.; Chen, X.; Dai, L. 3D graphene based materials for energy storage. Curr. Opin. Colloid Interface Sci. 2015, 20, 429-438. [CrossRef]

32. Lu, L.; De Hosson, J.T.M.; Pei, Y. Three-dimensional micron-porous graphene foams for lightweight current collectors of lithium-sulfur batteries. Carbon 2019, 144, 713-723. [CrossRef]

33. Li, G.; Huang, B.; Pan, Z.; Su, X.; Shao, Z.; An, L. Advances in three-dimensional graphene-based materials: Configurations, preparation and application in secondary metal ( $\mathrm{Li}, \mathrm{Na}, \mathrm{K}, \mathrm{Mg}, \mathrm{Al})$-ion batteries. Energy Environ. Sci. 2019, 12, 2030-2053. [CrossRef]

34. Ma, Y.; Chen, Y. Three-dimensional graphene networks: Synthesis, properties and applications. Natl. Sci. Rev. 2014, 2, 40-53. [CrossRef]

35. Xu, Y.; Sheng, K.; Li, C.; Shi, G. Self-assembled graphene hydrogel via a one-step hydrothermal process. ACS Nano 2010, 4, 4324-4330. [CrossRef] [PubMed]

36. Choi, B.G.; Yang, M.; Hong, W.H.; Choi, J.W.; Huh, Y.S. 3D macroporous graphene frameworks for supercapacitors with high energy and power densities. ACS Nano 2012, 6, 4020-4028. [CrossRef]

37. Chen, Z.; Ren, W.; Gao, L.; Liu, B.; Pei, S.; Cheng, H.M. Three-dimensional flexible and conductive interconnected graphene networks grown by chemical vapour deposition. Nat. Mater. 2011, 10, 424-428. [CrossRef]

38. Nardecchia, S.; Carriazo, D.; Ferrer, M.L.; Gutierrez, M.C.; del Monte, F. Three dimensional macroporous architectures and aerogels built of carbon nanotubes and/or graphene: Synthesis and applications. Chem. Soc. Rev. 2013, 42, 794-830. [CrossRef]

39. Patil, U.; Lee, S.C.; Kulkarni, S.; Sohn, J.S.; Nam, M.S.; Han, S.; Jun, S.C. Nanostructured pseudocapacitive materials decorated 3D graphene foam electrodes for next generation supercapacitors. Nanoscale 2015, 7, 6999-7021. [CrossRef]

40. Xu, J.; Wang, M.; Wickramaratne, N.P.; Jaroniec, M.; Dou, S.; Dai, L. High-performance sodium ion batteries based on a 3D anode from nitrogen-doped graphene foams. Adv. Mater. 2015, 27, 2042-2048. [CrossRef] [PubMed]

41. Paraknowitsch, J.P.; Thomas, A. Doping carbons beyond nitrogen: An overview of advanced heteroatom doped carbons with boron, sulphur and phosphorus for energy applications. Energy Environ. Sci. 2013, 6, 2839-2855. [CrossRef]

42. Mo, R.; Rooney, D.; Sun, K.; Yang, H.Y. 3D nitrogen-doped graphene foam with encapsulated germanium/nitrogen-doped graphene yolk-shell nanoarchitecture for high-performance flexible Li-ion battery. Nat. Commun 2017, 8, 13949. [CrossRef] [PubMed]

43. Zhang, J.; Li, C.; Peng, Z.; Liu, Y.; Zhang, J.; Liu, Z.; Li, D. 3D free-standing nitrogen-doped reduced graphene oxide aerogel as anode material for sodium ion batteries with enhanced sodium storage. Sci. Rep. 2017, 7, 4886. [CrossRef] [PubMed]

44. Zhang, X.; Wang, B.; Yuan, W.; Wu, J.; Liu, H.; Wu, H.; Zhang, Y. Reduced graphene oxide modified N-doped carbon foam supporting $\mathrm{TiO}_{2}$ nanoparticles as flexible electrode for high-performance Li/Na ion batteries. Electrochim. Acta 2019, 311, 141-149. [CrossRef]

45. Chu, S.; Zhong, Y.; Cai, R.; Zhang, Z.; Wei, S.; Shao, Z. Mesoporous and nanostructured $\mathrm{TiO}_{2}$ layer with ultra-high loading on nitrogen-doped carbon foams as flexible and free-standing electrodes for lithium-ion batteries. Small 2016, 12, 6724-6734. [CrossRef]

46. Guo, Y.; Guo, S.; Ren, J.; Zhai, Y.; Dong, S.; Wang, E. Cyclodextrin functionalized graphene nanosheets with high supramolecular recognition capability: Synthesis and host-guest inclusion for enhanced electrochemical performance. ACS Nano 2010, 4, 4001-4010. [CrossRef]

47. Wang, H.; Robinson, J.T.; Diankov, G.; Dai, H. Nanocrystal growth on graphene with various degrees of oxidation. J. Am. Chem. Soc. 2010, 132, 3270-3271. [CrossRef]

48. Heller, W.T.; Cuneo, M.; Debeer-Schmitt, L.; Do, C.; He, L.; Heroux, L.; Littrell, K.; Pingali, S.V.; Qian, S.; Stanley, C.; et al. The suite of small-angle neutron scattering instruments at Oak Ridge National Laboratory. J. Appl. Crystallogr. 2018, 51, 242-248. [CrossRef] 
49. Liu, K.; Tan, S.; Moon, J.; Jafta, C.J.; Li, C.; Kobayashi, T.; Lyu, H.; Bridges, C.A.; Men, S.; Guo, W.; et al. Insights into the enhanced cycle and rate performances of the F-substituted P2-type oxide cathodes for sodium-ion batteries. Adv. Energy Mater. 2020, 10, 2000135. [CrossRef]

50. Bi, H.; Yin, K.; Xie, X.; Zhou, Y.; Wan, N.; Xu, F.; Banhart, F.; Sun, L.; Ruoff, R.S. Low temperature casting of graphene with high compressive strength. Adv. Mater. 2012, 24, 5124-5129. [CrossRef]

51. Wu, F.; Zhou, J.; Luo, R.; Huang, Y.; Mei, Y.; Xie, M.; Chen, R. Reduced graphene oxide aerogel as stable host for dendrite-free sodium metal anode. Energy Storage Mater. 2019, 22, 376-383. [CrossRef]

52. Li, C.; Yang, J.; Pachfule, P.; Li, S.; Ye, M.Y.; Schmidt, J.; Thomas, A. Ultralight covalent organic framework/graphene aerogels with hierarchical porosity. Nat. Commun. 2020, 11, 4712. [CrossRef] [PubMed]

53. Kang, S.M.; Park, S.; Kim, D.; Park, S.Y.; Ruoff, R.S.; Lee, H. Simultaneous reduction and surface functionalization of graphene oxide by mussel-inspired chemistry. Adv. Funct. Mater. 2011, 21, 108-112. [CrossRef]

54. Wang, J.; Fei, G.; Pan, Y.; Zhang, K.; Hao, S.; Zheng, Z.; Xia, H. Simultaneous reduction and surface functionalization of graphene oxide by cystamine dihydrochloride for rubber composites. Compos. Part A Appl. Sci. 2019, 122, 18-26. [CrossRef]

55. Huang, H.H.; De Silva, K.K.H.; Kumara, G.R.A.; Yoshimura, M. Structural evolution of hydrothermally derived reduced graphene oxide. Sci. Rep. 2018, 8, 6849. [CrossRef]

56. Mori, F.; Kubouchi, M.; Arao, Y. Effect of graphite structures on the productivity and quality of few-layer graphene in liquid-phase exfoliation. J. Mater. Sci. 2018, 53, 12807-12815. [CrossRef]

57. Hinde, A.L. PRINSAS-A Windows-based computer program for the processing and interpretation of small-angle scattering data tailored to the analysis of sedimentary rocks. J. Appl. Crystallogr. 2004, 37, 1020-1024. [CrossRef]

58. Zhao, Y.; Wang, J.; Ma, C.; Li, Y.; Shi, J.; Shao, Z. Interconnected graphene nanosheets with confined FeS $2 / \mathrm{FeS}_{\text {binary nanoparticles }}$ as anode material of sodium-ion batteries. Chem. Eng. Sci. 2019, 378, 122168. [CrossRef] 